\title{
Surgical management for non-functional pancreatic neuroendocrine neoplasms with synchronous liver metastasis: A consensus from the Chinese Study Group for Neuroendocrine Tumors (CSNET)
}

KAIZHOU JIN $^{1 *}$, JIN XU $^{1 *}$, JIE CHEN $^{2}$, MINHU CHEN $^{2}$, RUFU CHEN $^{3}$, YE CHEN $^{4}$, ZHIYU CHEN $^{5}$, BIN CHENG $^{6}$, YIHEBALI CHI ${ }^{7}$, SHI-TING FENG ${ }^{8}$, DELIANG FU ${ }^{9}$, BAOHUA HOU $^{10}$, DAN HUANG ${ }^{11}$, HEGUANG HUANG ${ }^{12}$, QIANG HUANG ${ }^{13}$, JIE LI ${ }^{14}$, YING LI $^{15}$, HOUJIE LIANG ${ }^{16}$, RONG LIN ${ }^{17}$, AN'AN LIU ${ }^{18}$, JIXI LIU ${ }^{19}$, XUBAO LIU ${ }^{20}$, MING LU ${ }^{14}$, JIE LUO $^{21}$, GANG MAI $^{22}$, QUANXING NI ${ }^{1}$, MENG QIU ${ }^{23}$, CHENGHAO SHAO $^{18}$, BAIYONG SHEN ${ }^{24}$, WEIQI SHENG ${ }^{11}$, JIAN SUN ${ }^{3}$, CHUNLU TAN $^{20}$, HUANGYING TAN $^{25}$, QIYUN TANG $^{26}$, YINGMEI TANG $^{27}$, XIAODONG TIAN $^{28}$, DANIAN TONG $^{29}$, XIAOHONG WANG $^{30}$, JIAN WANG ${ }^{31}$, JIE WANG ${ }^{32}$, WEI WANG ${ }^{33}$, WEI WANG ${ }^{34}$, YU WANG ${ }^{35}$, ZHENG WU $^{36}$, LING XUE $^{37}$, QIANG YAN ${ }^{38}$, NING YANG ${ }^{39}$, YINMO YANG ${ }^{28}$, ZHIYING YANG $^{40}$, XIAOYI YIN $^{41}$, CHUNHUI YUAN ${ }^{42}$, SHAN ZENG $^{43}$, RENCHAO ZHANG ${ }^{44}$ and XIANJUN YU ${ }^{1}$

${ }^{1}$ Department of Pancreatic Surgery, Fudan University Shanghai Cancer Center; Pancreatic Cancer Institute, Fudan University; Department of Oncology, Shanghai Medical College, Fudan University, Shanghai; ${ }^{2}$ Department of Gastroenterology,

The First Affiliated Hospital, Sun Yat-sen University, Guangzhou, Guangdong; ${ }^{3}$ Department of Biliary-Pancreatic Surgery, Sun Yat-sen Memorial Hospital, Sun Yat-sen University, Guangzhou, Guangdong; ${ }^{4}$ Department of Gastroenterology, Nanfang Hospital, Southern Medical University, Guangzhou, Guangdong; ${ }^{5}$ Department of Medical Oncology, Shanghai Cancer Center, Fudan University, Shanghai; ${ }^{6}$ Department of Gastroenterology, Tongji Hospital, Tongji Medical College, Huazhong University of Science and Technology, Wuhan, Hubei; ${ }^{7}$ Department of Medical Oncology, Cancer Institute and Hospital, Chinese Academy of Medical Sciences, Beijing; ${ }^{8}$ Department of Radiology, The First Affiliated Hospital, Sun Yat-sen University, Guangzhou, Guangdong; ${ }^{9}$ Department of Pancreatic Surgery, Huashan Hospital, Fudan University, Shanghai; ${ }^{10}$ Department of General Surgery, Guangdong General Hospital, Guangzhou, Guangdong; ${ }^{11}$ Department of Pathology, Shanghai Cancer Center, Fudan University, Shanghai; ${ }^{12}$ Department of General Surgery, Fujian Medical University Union Hospital, Fuzhou, Fujian; ${ }^{13}$ Department of General Surgery, Anhui Provincial Hospital, Hefei, Anhui; ${ }^{14}$ Department of Gastrointestinal Oncology, Peking University Cancer Hospital and Beijing Cancer Hospital, Beijing; ${ }^{15}$ Department of Radiology, Peking University Cancer Hospital, Beijing; ${ }^{16}$ Department of Oncology, Southwest Hospital, Third Military Medical University, Chongqing; ${ }^{17}$ Department of Gastroenterology, Wuhan Union Hospital, Tongji Medical College, Huazhong University of Science and Technology, Wuhan, Hubei; ${ }^{18}$ Department of General Surgery, Changzheng Hospital, Second Military Medical University, Shanghai; ${ }^{19}$ Department of Gastroenterology, China-Japan Friendship Hospital, Beijing; ${ }^{20}$ Department of Hepatobiliopancreatic Surgery, West China Hospital, Sichuan University, Chengdu, Sichuan; ${ }^{21}$ Department of Pathology, China-Japan Friendship Hospital, Beijing; ${ }^{22}$ Department of Hepatobiliopancreatic Surgery, The People's Hospital of Deyang,

Chengdu, Sichuan; ${ }^{23}$ Department of Abdominal Oncology, Cancer Center, West China Hospital, Sichuan University, Chengdu, Sichuan; ${ }^{24}$ Department of General Surgery, Ruijin Hospital, Shanghai Jiao Tong University School of Medicine, Shanghai; ${ }^{25}$ Department of Integrative Oncology, China-Japan Friendship Hospital, Beijing; ${ }^{26}$ Department of Gastroenterology, Jiangsu People's Hospital, Nanjing, Jiangsu; ${ }^{27}$ Department of Gastroenterology, The Second Affliated Hospital of Kunming Medical University, Yunnan Research Center for Liver Diseases, Kunming, Yunnan;

Correspondence to: Dr Xianjun Yu, Department of Pancreatic Surgery, Fudan University Shanghai Cancer Center, 270 Dong An Road, Shanghai 200032, P.R. China

E-mail: yuxianjun@fudanpci.org

*Contributed equally

Key words: surgical management, non-functional pancreatic neuroendocrine neoplasms, synchronous liver metastasis, consensus, Chinese Study Group for Neuroendocrine Tumors (CSNET) 
${ }^{28}$ Department of General Surgery, Peking University First Hospital, Beijing; ${ }^{29}$ Department of Surgery, Shanghai Jiao Tong University Affiliated Sixth People's Hospital, Shanghai; ${ }^{30}$ Department of Radiology, Shanghai Cancer Center, Fudan University, Shanghai; ${ }^{31}$ Department of Biliary-Pancreatic Surgery, Renji Hospital, Shanghai Jiao Tong University School of Medicine, Shanghai; ${ }^{32}$ Department of Hepatobiliary Surgery, Sun Yat-sen Memorial Hospital, Sun Yat-Sen University, Guangzhou, Guangdong; ${ }^{33}$ Department of Surgery, Huadong Hospital, Fudan University, Shanghai; ${ }^{34}$ Department of Gastric and Pancreatic Surgery, Sun Yat-Sen University Cancer Center, Guangzhou, Guangdong; ${ }^{35}$ Department of Interventional Oncology, The First Affiliated Hospital, Sun Yat-sen University, Guangzhou Guangdong; ${ }^{36}$ Department of Hepatobiliary Surgery, The First Affiliated Hospital of Xi'an Jiaotong University, Xi'an, Shaanxi; ${ }^{37}$ Department of Pathology, The First Affiliated Hospital, Sun Yat-Sen University, Guangzhou, Guangdong; ${ }^{38}$ Department of Hepatobiliopancreatic Surgery, Huzhou Central Hospital, Huzhou, Zhejiang; ${ }^{39}$ Hepatobiliary Surgery Department V, Eastern Hepatobiliary Surgery Hospital, Shanghai; ${ }^{40}$ Department of Hepatobiliary Surgery, China-Japan Friendship Hospital, Beijing; ${ }^{41}$ Department of Biliary-

Pancreatic Surgery, The First Affiliated Hospital, Sun Yat-Sen University, Guangzhou, Guangdong;

${ }^{42}$ Department of General Surgery, Peking University Third Hospital, Beijing; ${ }^{43}$ Department of Oncology,

Xiangya Hospital, Central South University, Changsha, Hunan; ${ }^{44}$ Department of Gastrointestinal and Pancreatic Surgery, Zhejiang Provincial People's Hospital, Hangzhou, Zhejiang, P.R. China

Received July 30, 2016; Accepted September 19, 2016

DOI: $10.3892 /$ ijo.2016.3711

\begin{abstract}
Pancreatic neuroendocrine neoplasms (p-NENs) are slowly growing tumors with frequent liver metastasis. There is a variety of approaches to treat non-functional p-NENs with synchronous liver metastasis (LM) which complicates the determination of optimal treatment. Based on updated literature review, we discussed the treatment strategy determinants for p-NEN with LM. According to the resectability of primary tumor, the WHO 2010 grade classification and the radiological type of liver metastasis, the CSNET group reached agreements on a number of issues, including the following. Prior to treatment, biopsy is required to confirm pathology. Liver biopsy is important for more accurate grading of tumor and percutaneous core needle biopsy is more available than EUS-FNA. In patients with unresectable primary, surgical resection for liver-metastatic lesions should be avoided. Curative surgery is recommended for G1/G2 p-NET with type I LM and R1 resection also seems to improve overall survival rate. Cytoreductive surgery is recommended for G1/G2 p-NET with type II LM in select patients, and should meet stated requirements. Surgical resection for G1/G2 p-NET with type III LM and p-NEC with LM should be avoided, and insufficient evidence exists to guide the surgical treatment of G3 p-NET with LM. Liver transplantation may be an option in highly select patients. In addition, the optimal time for surgical approach is still required for more evidence.
\end{abstract}

\section{Introduction}

The incidence of pancreatic neuroendocrine neoplasms (p-NENs), which originate from pancreatic neuroendocrine cells, has been increasing over the last 20 years $(1,2)$. The vast majority of p-NENs are non-functioning, with symptoms stemming from distant metastases or mass effects $(3,4)$. In metastatic p-NENs, liver is the most important location for metastatic disease and LM is frequently observed in p-NEN patients (5-7).
Having low mortality and complication rates, surgery for local p-NENs has long been the standard treatment strategy (8). In recent decades, technological improvements have also improved surgical success for liver-metastatic p-NENs, which has an overall mortality rate of $<5 \%(9,10)$.

To allow for more specific and individualized treatment of liver-metastatic p-NENs, Frilling et al (11) classified them into three radiological types. Type I is defined as a single metastasis regardless of size. Type II is defined as an isolated metastatic bulk accompanied by smaller deposits. Type III is defined as a disseminated metastatic spread. These three groups differ significantly in terms of treatment strategies and clinical outcomes (12).

Pathological classification is another key prognostic factor in p-NENs (13). In 2010, the WHO updated their grading system for the pathological classification of $\mathrm{p}-\mathrm{NEN}$ based on the Ki-67 index and mitotic counts (14). A pancreatic carcinoid is now defined as G1/G2 p-NET, while small-cell or large-cell neuroendocrine carcinoma is defined as G3 p-NEC. Tumors with a Ki-67 index of $\leq 2 \%, 3-20 \%$ or $>20 \%$ are classified as $\mathrm{G} 1, \mathrm{G} 2$ and $\mathrm{G} 3$, respectively. While a group of well-to-moderately differentiated G3 p-NETs respond more poorly to chemotherapy than poorly differentiated G3 p-NEC, they are nevertheless associated with longer median survival (15). This group of G3 p-NETs may be considered separate from p-NEC (16). In 2013, 15 Chinese pathology experts reached the consensus for NET G3 and defined it as NET with high proliferative activity.

Despite the existence of various guidelines and comprehensive reviews addressing surgical management for non-functional p-NENs with synchronous LM, the best strategy is still poorly defined. In the present study, we report the findings of a panel of multidisciplinary experts from CSNET who assessed available evidence with the aim of developing recommendations for the surgical management of patients with liver-metastatic p-NENs. Consensus statements were developed that take into consideration the radiological 
type of liver metastasis, the WHO 2010 grade classification and the resectability of the primary tumor.

\section{Materials and methods}

The PubMed database was searched for studies relating to the treatment of p-NENs with LM by entering the terms including (pancreatic neuroendocrine tumor OR neuroendocrine tumor OR carcinoma), (operative OR surgical, operative surgical OR pancreatectomies OR pancreaticoduodenectomy OR pancreaticoduodenectomies OR duodenopancreatectomy OR duodenopancreatectomies OR primary resection), (metastatic OR metastasis OR metastases), (neoplasm OR neoplasms), and (liver OR hepatic). Randomized trials, reviews and observational studies were included. Studies published in English were reviewed and selected for further screening analyses and for subsequent consensus studies. Data extraction was carried out by all experts in CSNET.

\section{Results and Consensus statements}

Pathological confirmation. Endoscopic ultrasound-guided fine-needle aspiration (EUS-FNA) and percutaneous core needle biopsy are two common methods for obtaining tissue samples in p-NENs (17).

EUS-FNA has become a successful approach in establishing a definitive tissue diagnosis of p-NENs for more than 20 years (18). Several retrospective studies have shown advantages of EUS-FNA, including generation of high-resolution images enabling detection of small lesions (19-21). However, EUS-FNA has an accuracy fluctuation dependent upon the tumor type. Diagnostic accuracy is lower for p-NENs (46.7\%) than for adenocarcinomas (81.4\%) (22). The accuracy in the grading of p-NENs (the concordance rate between EUS-FNA samples and surgical specimens) is also unsatisfactory (23), especially without adequate cellularity (24). Only when more than 2000 tumor cells obtained by EUS-FNA may increase the accuracy of tumor grading (24). Therefore, due to the small amount of tissue obtained from EUS-FNA, it remains unclear if EUS-FNA samples truly reflect the entire tumor.

In comparison, percutaneous core needle biopsy has relatively greater availability, lower cost, a higher success rate, enables access to sufficient material and allows access to lesions in any part of the pancreas $(17,25-27)$. Sufficient material can be extracted to determine cell type and origin via histologic and immunohistochemical analyses, thus, allowing for reliable differentiation of p-NENs (28). Moreover, collecting sufficient tissue may also decrease the difference between percutaneous core needle biopsy and surgical specimens.

There is no guideline as to whether liver-metastatic lesions should be biopsied for tumor grading in cases of liver-metastatic p-NENs and several studies have considered the homogeneity of the Ki-67 staining expression between primaries and metastases $(29,30)$. Nevertheless, Zen et al (31) reported that biopsy of liver metastasis may yield a higher $\mathrm{Ki}-67$ index than that in primary tumor; moreover, increased $\mathrm{Ki}-67$ index in liver metastases is associated with a poorer prognosis. Similar results were also reported in another two retrospective studies $(32,33)$. Therefore, liver biopsy is required for an accurate evaluation and biopsies of both primary tumors and metastatic tumors was recommended by a Canadian National Expert Group (34).

According to the ENETS 2012 guidelines, pathological classification (either primary tumor or metastatic lesions) should be confirmed before treatment, as only G1/G2 are recommended for operation in liver-metastatic p-NENs (35). The updated NCCN guidelines (8), NANETS guidelines (36), and the European Society for Medical Oncology (ESMO) (37) guidelines all suggest that Ki-67 assessment is required in liver-metastatic p-NENs, no matter which method is used.

Consensus statements. Biopsy for $\mathrm{Ki}-67$ assessment is required in liver-metastatic p-NENs before a treatment decision is made. Liver biopsy is important for more accurate grading of tumors in patients with LM. Percutaneous core needle biopsy is more available than EUS-FNA.

Liver-metastatic p-NENs with unresectable primary tumor. The aim of the surgery for non-functional p-NENs with LM is to prolong overall survival through potential curative resection or cytoreduction. Previous reports showed that survival benefits were observed for R0/R1 resection (38). Nevertheless, for liver-metastatic p-NENs with an unresectable primary, surgical resection of the metastases is always considered as less effective.

No guideline from ENETS (39), NANETS (40), or NCCN (8) reports any survival benefit associated with cytoreductive resection only for liver metastases per se. In the 2010 UICC/AJCC/WHO TNM staging system (41), stage T4 was defined as unresectable tumor with the involvement of the celiac axis or the superior mesenteric artery. Tumorinvading adjacent organs (stomach, spleen, colon and adrenal gland) were also grouped in T4 in the ENETS staging system; surgery should not be performed in patients with a T4 primary tumor (42). Multiphasic CT or MRI are recommended to preoperative evaluation (8).

Consensus statements. If the primary tumor is $\mathrm{T} 4$, surgical resection for liver-metastatic lesions should be avoided, and this should be carefully assessed preoperatively. Whether R2 resection to the primary improves prognosis is not yet clear.

G1/G2 p-NET with type I LM. Unlike pancreatic adenocarcinoma, when the R0 resection is possible, surgery may also be considered in part of patients with G1/G2 liver-metastatic p-NET. Type I metastasis is defined as one metastatic lesion regardless of size (11). Generally, for type I metastasis, surgical treatment should be undertaken with the goal of an R0 resection (12).

An early study of 16 patients recommended aggressive surgery as the first choice for G1/G2 liver-metastatic p-NET (43). If the metastasis is unilobar, LM can be resected at the same time as the primary tumor with little additional risk (44).

When an R0 resection can be achieved (all macroscopic disease is removed and surgical margins are negative for microscopic disease), G1/G2 liver-metastatic p-NET patients can benefit from improved long-term survival compared to patients with unresected disease, as confirmed by several 
retrospective studies $(45,46)$. Furthermore, another relatively large-scale study prospectively reported there were no differences in survival found between R0 and R1 resection. Both R0 and $\mathrm{R} 1$ resection can be beneficial (38).

In recent years, ENETS issued general guidelines for patients with hepatic involvement of type I, with surgical resection being the first therapeutic option (39). Despite the lack of randomized data, the ENETS consensus statement emphasized that a curative resection for type I liver metastasis should be the first-line treatment option $(39,47)$. Since then, curative surgery in G1/G2 p-NET with type I LM has been accepted in clinical practice.

Additional studies published in last decade have demonstrated the advantage of surgery in type I liver-metastatic p-NET. Patients can have 3- and 5-year overall survival rates of up to $100 \%$ if $\mathrm{R} 0 / \mathrm{R} 1$ resection is performed $(11,45)$. However, the 5- and 10-year recurrence rate was 84 and $94 \%$, respectively, even if an $\mathrm{R} 0$ resection was performed (48). This high postoperative recurrence should be noted.

Also, laparoscopic surgery, which has a similar surgical complication rate and short-term prognosis as compared to open surgery, is also a practical option for the treatment of p-NET with type I LM (49).

Consensus statements. Curative surgery is recommended for resectable G1/G2 p-NET with type I LM. While R0 resection is the aim of the operation, $\mathrm{R} 1$ resection also seems to improve the overall survival rate.

G1/G2 p-NET with type II LM. Compared to type I metastasis, curative surgery may not always be performed in patients with type II LM. Only for unilobar metastatic lesions, curative surgery is the goal just like that in type I liver-metastatic p-NETs. Therefore, regarding type II liver-metastatic p-NETs, whether cytoreductive surgery can be of benefit needs to be determined.

In early 1996, liver resection in patients with a metastatic neuroendocrine tumor was recommended to provide good long-term symptom palliation (50). In general, cytoreductive surgery for liver-metastatic p-NET is indicated to reduce hormone levels and improve clinical symptoms $(51,52)$. The effects on the prognosis are still debatable $(51,53,54)$.

Furthermore, hepatic resection, used in cytoreductive surgery, may come at the cost of high morbidity and mortality (55), especially when combined with the pancreaticoduodenectomy (56). A study of 120 p-NET patients reported that cytoreductive surgery carried significant perioperative mortality (6\%) and complication rates (43\%) without long-term survival benefits, and should be discouraged (53).

Nevertheless, with the development of surgical technology, improved long-term survival of patients with type II livermetastatic p-NET after cytoreductive surgery has also been recently reported. In a prospective, multicenter study from Zerbi et al (57), the 2-year prognosis of patients undergoing cytoreductive surgery was satisfactory and cytoreductive surgery for patients with low Ki-67 staining may achieve a statistically improved OS. In another relatively larger retrospective study of 72 patients with metastatic non-functional p-NETs from the Mayo Clinic, there was no difference in overall survival in patients undergoing cytoreductive surgery vs. those undergoing R0 resections, despite a higher incidence of tumor recurrence in the cytoreductive surgery group (58). Therefore, some researchers believe cytoreductive surgery should be pursued whenever possible, even if curative resection may not be achievable.

To identify the population that may benefit from the operation, Mayo et al (59) compared patients who underwent liver resection $(n=339)$ with those who underwent intra-arterial therapy (IAT) $(\mathrm{n}=414)$. Their data indicated that non-functional p-NET patients with low $(<25 \%)$ liver involvement benefited most from surgery, while patients with a large $(>25 \%)$ burden of liver metastases benefited the least from surgery. Tumor volume with $<25 \%$ liver involvement was identified as a useful selection criterion for patients who may benefit from cytoreductive surgery $(55,60)$. Other researchers also considered the tumor volume as one of key prognostic factors (5).

In order for treatment to be successful, cytoreductive surgery is required to remove at least $90 \%$ of the tumor, including not only liver metastases, but the primary tumor and lymph nodes $(46,52,61)$. ENETS, NCCN and NANETS guidelines have recommended $90 \%$ reduction of all visible tumors $(8,35,36)$. However, securing a $90 \%$ reduction is relatively difficult, and such a reduction may only be practical for less than $10 \%$ of patients $(5,35,36,48)$.

Nevertheless, a recent study of 108 pancreatic and small bowel NET patients showed that where $70 \%$ cytoreduction was achieved (in nearly two-thirds of p-NET cases), patients enjoyed improved progression-free survival (median 3.0 years). Also, it is worth noting that there was no perioperative mortality (55). Similar results also suggested that a 70\% or greater reduction of the tumor burden was enough to prolong survival and should be considered in the surgical strategy $(55,62-64)$. According to ESMO guidelines, excision of $>70 \%$ of the tumor load is recommended to improve combined treatment (37).

Liver surgery can be performed as either a one-step or a two-step procedure. For unilobar metastases and during a low-risk operation, resection for LM can be performed at the same time as the primary. If major or complex liver resection is required, a two-stage surgery may be preferable in order to reduce the operative risk, especially in patients with type II metastases (65). The two-step surgery may include a resection of the primary tumor, lymph nodes and metastases of one lobe. Then, contralateral liver volume, enhanced by right portal venous embolization hypertrophy, after that, right hepatectomy or lobectomy may be performed as a second step (66). Such an approach can benefit patients with bilobar metastases and avoid or delay indications for LT (67).

In an effort to achieve loco-regional control, cytoreductive surgery in combination with liver-directed therapies may also be considered. Combination approaches to cytoreduction are very effective and are associated with similar survival rates as those that use R0 resection only. Recent reports of cytoreduction that use resection and ablation or resection combined with other liver-directed therapy demonstrated a 5-year survival rate of $\sim 75 \%(62,68,69)$, which was comparable to those undergoing $\mathrm{R} 0$ resection (46).

An estimate of the remnant liver parenchyma volume is another factor in surgical decision making. Studies have reported that up to $70 \%$ of the whole liver volume can be safely removed by specialized liver surgeons $(63,64)$. A 
Table I. Selection criteria and requirements for cytoreduction in p-NETs with type II LM.

Selection criteria

G1/G2 p-NET with LM;

The primary is resectable;

No unresectable extrahepatic disease;

Younger patients with an acceptable morbidity and low mortality;

Tumor volume $<25 \%$ liver involvement;

Up to $90 \%$ when possible or $>70 \%$ of tumor load is thought resectable preoperatively;

Treatment decision making requires a multidisciplinary approach.

Requirements

Up to $90 \%$ when possible or $>70 \%$ tumor volume is required to be excised;

One-stage or two-stage surgery may be recommended;

Liver-directed therapies are complements to cytoreduction;

A remnant functional liver parenchyma volume should be at least $30 \%$ of the entire liver.

remnant functional liver parenchyma volume should be at least $30 \%$ of the entire liver volume to ensure the safety of operation. Therefore, more remnant functional liver parenchyma volume is required for the patient with impaired hepatic function.

ENETS guidelines have established and updated the essential criteria for patient selection. NCCN guidelines also recommend non-curative debulking surgery in select cases of type II liver-metastatic p-NET. According to guidelines and related studies $(8,47,54,70-72)$, the minimum criteria for cytoreductive surgery of liver-metastatic p-NETs are as follows (Table I): i) G1/G2 liver-metastatic p-NET; ii) the primary is resectable; iii) no unresectable extrahepatic disease; iv) younger patients with an acceptable morbidity and low mortality; v) tumor volume with $<25 \%$ liver involvement; vi) up to $90 \%$ or at least $>70 \%$ of tumor load is thought to be resectable preoperatively; and vii) treatment decision making requires a multidisciplinary approach.

Consensus statements. Curative surgery is the goal and cytoreduction should also be performed in select patients (Table I). For cytoreduction, the following requirements should also be met (Table I): i) up to $90 \%$ or at least $>70 \%$ of the tumor volume needs to be excised; ii) either one-stage or two-stage surgery may be recommended; iii) liver-directed therapies are complements to cytoreduction in surgical effectiveness; and iv) a remnant functional liver parenchyma volume should be at least $30 \%$ of the entire liver.

G1/G2 p-NET with type III LM. Type III liver-metastatic p-NET is defined as p-NET with disseminated metastatic spread in the liver. It is generally believed that there is limited potential for palliative hepatic resection due to excessive loss of functional liver parenchyma volume.

Both the guidelines of ENETS and NANETS currently do not make any recommendations on whether the primary tumor should be removed in this clinical scenario $(36,39)$. They also currently do not recommend routine resection in patients with type III liver-metastatic p-NET (resection of the primary alone fails to improve survival). Furthermore, standard resection in the presence of unresectable metastatic disease is also not suggested in the NCCN 2015 guidelines (8).

However, recent retrospective data suggest that resection of the pancreatic primary is associated with improved survival rate in p-NET patients with disseminated and unresected liver-metastases $(73,74)$. Patients undergoing surgical resection of the primary tumor had a better 5-year survival rate than patients with no resection (55-82 vs. 30-50\%) (73). These studies suggest that resection of the primary tumor may be beneficial even in the case of globally unresectable livermetastatic lesions.

Consensus statements. Available evidence does not support standard resection for type III liver-metastatic p-NET. Whether these patients benefit from removal of their primary tumor remains to be demonstrated.

G3 p-NET with LM. p-NET G3 is characterized by a Ki-67 index in the $\mathrm{G} 3$ range ( $\mathrm{Ki}-67$ index always $<55 \%$ ) and a mitotic rate suggestive of G2. p-NET G3 is significantly less aggressive than poorly differentiated NECs and is not defined in the WHO 2010 classification $(54,75)$. Prognostic outcomes associated with cases of p-NET G3 are much better than that of p-NEC (16). A multicenter study that included 37 NETs G3 and 167 NECs found that the median Ki-67 index was significantly different ( $30 \%$ in NET G3 vs. $80 \%$ in NEC), and that overall survival was also significantly higher in NET G3 (99 months in NET G3 vs. 17 months in NEC) (76).

Further details on the management of G3 p-NET have been summarized in a recently published comprehensive review (77), albeit without any definite recommendations related to surgical treatment. In the 2016 ENETS guidelines, chemotherapy and radiotherapy, rather than surgery, were suggested in cases of p-NET G3 with distant metastases (16).

Consensus statements. There is insufficient data relating to the value of surgery in the treatment of G3 p-NET; therefore, 


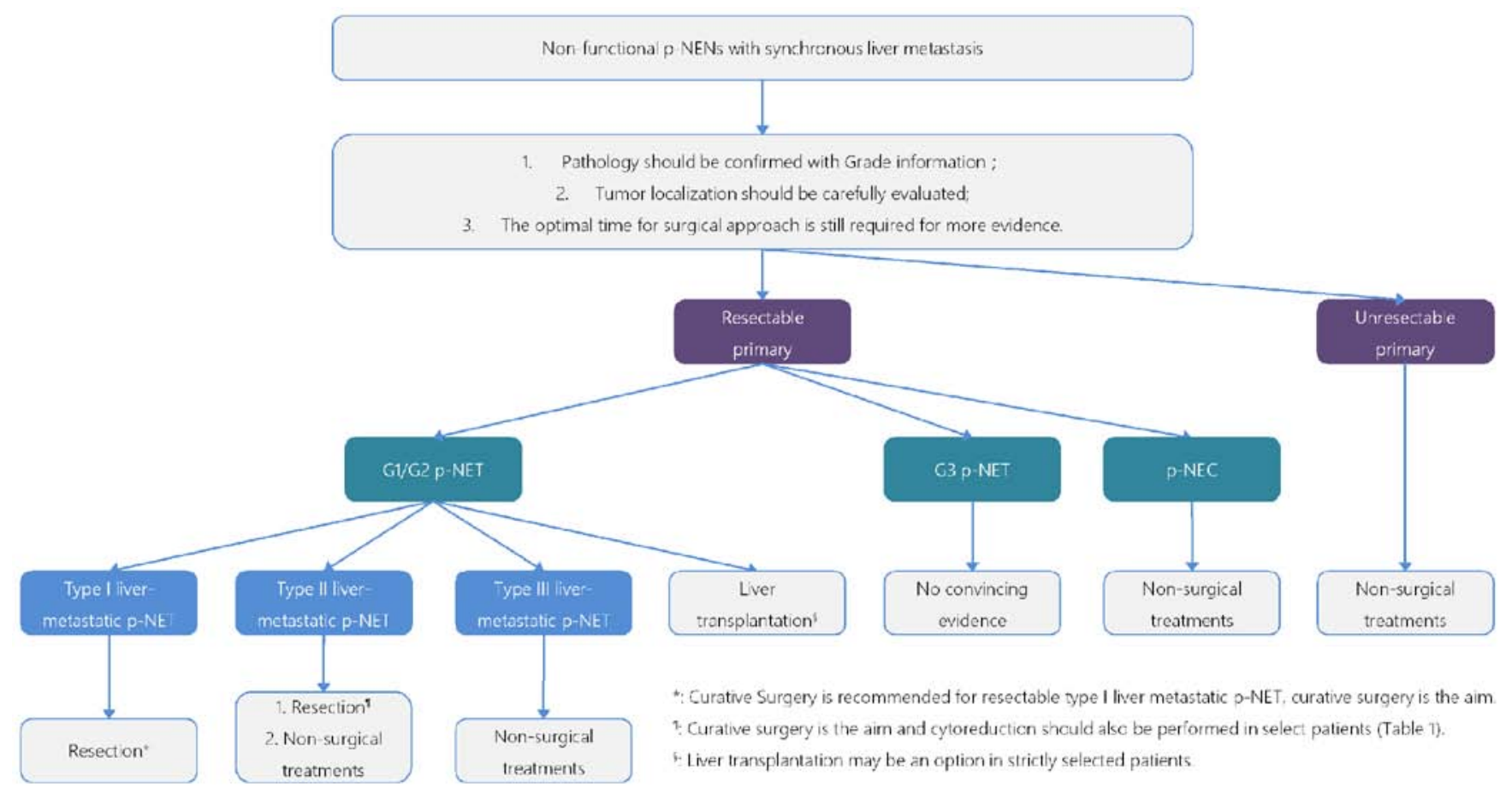

Figure 1. Treatment approach to non-functional p-NENs with synchronous liver metastasis.

studies are needed that investigate the effect of surgery patient survival in cases of liver-metastatic G3 p-NET.

G3 $p$-NEC with LM. Compared to G3 p-NET, p-NEC is highly malignant and has a poor prognosis and this results in there being distinct treatment strategies for p-NET vs. p-NEC. Therefore, an accurate grade classification is also required before making a treatment decision for liver-metastatic p-NENs (1).

p-NECs are highly malignant neoplasms that typically invade adjacent structures or have frequently metastasized at diagnosis (78).

Surgery is recommended, along with postoperative chemotherapy, for p-NEC with local disease (40). Generally, p-NEC with LM is considered not amenable for resection due to high recurrence rates and no overall survival benefit (79-81).

ENETS guidelines (81) for the surgical treatment of p-NEC refer to only two early studies $(82,83)$, and state that 'curative surgery should be attempted only in localized disease'. NANETS and NCCN guidelines do not mention surgical options for the treatment of liver metastatic p-NEC $(8,80)$. Moreover, the ESMO guidelines also agree that 'it is a general agreement not to operate on G3 p-NEC' (37).

Other recent studies report that multifocal and even diffuse disseminated hepatic lesions are common for p-NEC, which leads to a low rate of surgical intervention (84). Systemic therapy is recommended as the primary course of therapy in the majority of studies (79-81).

Nevertheless, in 2015, a Chinese retrospective study of 36 GEP-NEC with liver metastases patients suggested that aggressive cytoreductive surgery, as well as radiofrequency ablation and liver-directed intra-arterial intervention, may improve clinical outcomes (84).
A study of the largest cohort of patients with advanced p-NEC to date was recently published. The authors demonstrated that resection of the primary tumor was an independent prognostic factor in improved survival for patients with $\mathrm{p}$-NEC at different disease stages (85). These results suggest that resection of localized p-NEC and p-NEC with LM should both be considered.

However, it is worth noting that these two retrospective studies did not distinguish p-NET G3 from p-NEC. Not separating p-NET G3 from all G3 patients may lead to bias in the results.

Consensus statements. Surgical strategy is not mentioned in guidelines for the treatment of p-NEC with LM. Large randomized studies are required to fully justify the role of surgery in liver-metastatic p-NEC.

LT for p-NET with LM. LT for patients with metastatic neuroendocrine tumors was first reported in 1993 (86). Later, in 1998, Lehnert (87) reported a 2- and a 5-year survival rate of 44 and $30 \%$ in a series of 48 patients transplanted for p-NET with LM; however, recurrence rate was found to be high. For unresectable liver-metastatic lesions, whether LT is an option in patients with type II or III liver metastases is still unclear.

Several retrospective and prospective studies have shown encouraging results with a 5-year overall survival between 67 and $90 \%$ and a low 5-year recurrence-free survival rate between 20 and 48\% (88-91). Recently, a relatively largesample study reviewed 94 patients who had undergone LT for liver-metastatic p-NET in 35 centers between 1982 and 2009. The overall three-month postoperative mortality was $10 \%$. At 5 years after LT, overall survival was $52 \%$, while disease-free survival was only $30 \%$ (92).

Due to the scarcity and heterogeneity of reported cases of LT and the lack of randomized trials, controversy continues 
surrounding patient selection for LT. NCCN guidelines recommend that LT should not be included amongst routine treatment strategies (8). In the ENETS and NANETS guidelines, LT is also generally not recommended as a routine treatment option in p-NEN with LM; rather, it may only be an option in highly selected patients $(36,39)$.

The minimal selection criteria are as follows: i) welldifferentiated p-NETs with Ki-67 $<10 \%$; ii) age $<55$ years; iii) absence of extrahepatic disease; iv) primary tumor removed before transplantation; v) stable disease for at least six months before LT; vi) $<50 \%$ liver involvement $(39,93)$. Unfortunately, these selection criteria have not been validated in large prospective studies.

Consensus statements. LT is generally not recommended as a routine treatment option in liver-metastatic p-NENs; it may be an option in strictly select patients.

Appropriate timing for aurgical approach. It is still controversial how to determine the best timing of a surgical approach, and we still do not have enough data nor research regarding this topic.

In ENETS guidelines, debulking surgery may be considered if the disease is not progressive over a 6-month period and the patients are suffering from symptoms related to tumor burden (55). However, the evidence is still insufficient. In some cases the surgical approach could be carried out first, while other patients may benefit from pre-operative medical treatments or observations of tumor biologic behavior. Therefore, multidisciplinary discussion is required to determine the best choice of treatment (8) and re-evaluating for the treatment's effectiveness of a surgical approach is also required.

Consensus statements. Due to insufficient evidence, the appropriate time for surgical approach is still unclear.

\section{Conclusions}

Surgical management of liver-metastatic p-NENs still lacks consensus recomendations. Slow growth of the tumor and the availability of numerous effective treatment strategies make determination complicated of the optimal treatment. Different combinations of liver metastases types, localization, and pathological classification have different outcomes and require different treatment strategies. Surgical resection may be an optimal treatment option for some patients with livermetastatic p-NENs. Based on the existing evidence, experts in CSNET have reached an agreement regarding the following treatment aspects (Fig. 1):

Biopsy in p-NEN with LM: i) biopsy is essential prior to treatment to confirm pathology; ii) liver biopsy is important for the accuracy of tumor grading; iii) percutaneous core needle biopsy procedure maybe more available in comparison to EUS-FNA.

Liver-metastatic p-NEN with unresectable primary: i) surgical resection for liver-metastatic lesions should be avoided.

G1/G2 p-NET with type I LM: i) curative surgery is recommended; ii) curative resection (R0 resection) is the aim of the operation; iii) R1 resection seems to contribute to the overall survival rate.
G1/G2 p-NET with type II LM: i) curative surgery is also the goal; ii) cytoreductive surgery is recommended in select patients and should meet requirements (Table I).

G1/G2 p-NET with type III LM: Surgical resection should be avoided.

G3 p-NET with LM: There is insufficient data to guide recommendations on surgical treatment.

p-NEC with LM: Surgical resection is not currently recommended.

LT in liver-metastatic p-NEN: LT may be an option in strictly selected patients for liver-metastatic p-NET.

Appropriate timing for surgical approach: The optimal time for surgery still requires more evidence.

\section{References}

1. Yao JC, Hassan M, Phan A, Dagohoy C, Leary C, Mares JE, Abdalla EK, Fleming JB, Vauthey JN, Rashid A, et al: One hundred years after 'carcinoid': Epidemiology of and prognostic factors for neuroendocrine tumors in 35,825 cases in the United States. J Clin Oncol 26: 3063-3072, 2008.

2. Tsai HJ, Wu CC, Tsai CR, Lin SF, Chen LT and Chang JS: The epidemiology of neuroendocrine tumors in Taiwan: A nationwide cancer registry-based study. PLoS One 8: e62487, 2013.

3. Modlin IM, Oberg K, Chung DC, Jensen RT, de Herder WW, Thakker RV, Caplin M, Delle Fave G, Kaltsas GA, Krenning EP, et al: Gastroenteropancreatic neuroendocrine tumours. Lancet Oncol 9: 61-72, 2008.

4. Halfdanarson TR, Rabe KG, Rubin J and Petersen GM: Pancreatic neuroendocrine tumors (PNETs): Incidence, prognosis and recent trend toward improved survival. Ann Oncol 19: 1727-1733, 2008

5. Chamberlain RS, Canes D, Brown KT, Saltz L, Jarnagin W, Fong Y and Blumgart LH: Hepatic neuroendocrine metastases: Does intervention alter outcomes? J Am Coll Surg 190: 432-445, 2000.

6. Modlin IM, Lye KD and Kidd M: A 5-decade analysis of 13,715 carcinoid tumors. Cancer 97: 934-959, 2003.

7. Oberg K and Eriksson B: Endocrine tumours of the pancreas. Best Pract Res Clin Gastroenterol 19: 753-781, 2005.

8. Kulke MH, Shah MH, Benson AB III, Bergsland E, Berlin JD, Blaszkowsky LS, Emerson L, Engstrom PF, Fanta P, Giordano T, et al; National Comprehensive Cancer Network: Neuroendocrine tumors, version 1.2015. J Natl Compr Cancer Netw 13: 78-108, 2015.

9. Nave H, Mössinger E, Feist H, Lang H and Raab H: Surgery as primary treatment in patients with liver metastases from carcinoid tumors: A retrospective, unicentric study over 13 years. Surgery 129: 170-175, 2001.

10. Capurso G, Bettini R, Rinzivillo M, Boninsegna L, Delle Fave G and Falconi M: Role of resection of the primary pancreatic neuroendocrine tumour only in patients with unresectable metastatic liver disease: A systematic review. Neuroendocrinology 93: 223-229, 2011.

11. Frilling A, Li J, Malamutmann E, Schmid KW, Bockisch A and Broelsch CE: Treatment of liver metastases from neuroendocrine tumours in relation to the extent of hepatic disease. Br J Surg 96: 175-184, 2009.

12. Frilling A, Modlin IM, Kidd M, Russell C, Breitenstein S, Salem R, Kwekkeboom D, Lau WY, Klersy C, Vilgrain V, et al; Working Group on Neuroendocrine Liver Metastases: Recommendations for management of patients with neuroendocrine liver metastases. Lancet Oncol 15: e8-e21, 2014.

13. Martin-Perez E, Capdevila J, Castellano D, Jimenez-Fonseca P, Salazar R, Beguiristain-Gomez A, Alonso-Orduña V, Martinez Del Prado P, Villabona-Artero C, Diaz-Perez JA, et al; The Large Experience of the Spanish National Tumor Registry (RGETNE): Prognostic factors and long-term outcome of pancreatic neuroendocrine neoplasms: Ki-67 index shows a greater impact on survival than disease stage. The large experience of the Spanish National Tumor Registry (RGETNE). Neuroendocrinology 98: 156-168, 2013. 
14. Rindi G, Arnold R and Bosman FT: Nomenclature and classification of neuroendocrine neoplasms of the digestive system. In: WHO Classification of Tumours of the Digestive System. Bosman FT, Carneiro F, Hruban RH and Theise ND (eds). IARC, Press, Lyon, 2010.

15. Tang LH, Untch BR, Reidy DL, O'Reilly E, Dhall D, Jih L, Basturk O, Allen PJ and Klimstra DS: Well-differentiated neuroendocrine tumors with a morphologically apparent high-grade component: A pathway distinct from poorly differentiated neuroendocrine carcinomas. Clin Cancer Res 22: 1011-1017, 2016.

16. Garcia-Carbonero R, Sorbye H, Baudin E, Raymond E, Wiedenmann B, Niederle B, Sedlackova E, Toumpanakis C, Anlauf M, Cwikla JB, et al; Vienna Consensus Conference participants: ENETS Consensus guidelines for high-grade gastroenteropancreatic neuroendocrine Tumors and neuroendocrine carcinomas. Neuroendocrinology 103: 186-194, 2016.

17. Goldin SB, Bradner MW, Zervos EE and Rosemurgy AS II: Assessment of pancreatic neoplasms: Review of biopsy techniques. J Gastrointest Surg 11: 783-790, 2007.

18. Rösch T, Lightdale CJ, Botet JF, Boyce GA, Sivak MV Jr, Yasuda K, Heyder N, Palazzo L, Dancygier H, Schusdziarra V, et al: Localization of pancreatic endocrine tumors by endoscopic ultrasonography. N Engl J Med 326: 1721-1726, 1992.

19. Chang KJ, Albers CG, Erickson RA, Butler JA, Wuerker RB and Lin F: Endoscopic ultrasound-guided fine needle aspiration of pancreatic carcinoma. Am J Gastroenterol 89: 263-266, 1994.

20. Chatzipantelis P, Salla C, Konstantinou P, Karoumpalis I, Sakellariou S and Doumani I: Endoscopic ultrasound-guided fine-needle aspiration cytology of pancreatic neuroendocrine tumors: A study of 48 cases. Cancer 114: 255-262, 2008.

21. Jani N, Khalid A, Kaushik N, Brody D, Bauer K, Schoedel K, Ohori NP, Moser AJ, Lee K and McGrath K: EUS-guided FNA diagnosis of pancreatic endocrine tumors: New trends identified. Gastrointest Endosc 67: 44-50, 2008.

22. Voss M, Hammel P, Molas G, Palazzo L, Dancour A, O'Toole D, Terris B, Degott C, Bernades P and Ruszniewski P: Value of endoscopic ultrasound guided fine needle aspiration biopsy in the diagnosis of solid pancreatic masses. Gut 46: 244-249, 2000

23. Fujimori N, Osoegawa T, Lee L, Tachibana Y, Aso A, Kubo H, Kawabe K, Igarashi H, Nakamura K, Oda Y, et al: Efficacy of endoscopic ultrasonography and endoscopic ultrasonographyguided fine-needle aspiration for the diagnosis and grading of pancreatic neuroendocrine tumors. Scand J Gastroenterol 51: 245-252, 2016

24. Hasegawa T, Yamao K, Hijioka S, Bhatia V, Mizuno N, Hara K, Imaoka H, Niwa Y, Tajika M, Kondo S, et al: Evaluation of Ki-67 index in EUS-FNA specimens for the assessment of malignancy risk in pancreatic neuroendocrine tumors. Endoscopy 46: 32-38, 2014.

25. Tyng CJ, Almeida MF, Barbosa PN, Bitencourt AG, Berg JA, Maciel MS, Coimbra FJ, Schiavon LH, Begnami MD Guimarães MD, et al: Computed tomography-guided percutaneous core needle biopsy in pancreatic tumor diagnosis. World $\mathrm{J}$ Gastroenterol 21: 3579-3586, 2015.

26. Yang RY, Ng D, Jaskolka JD, Rogalla P and Sreeharsha B Evaluation of percutaneous ultrasound-guided biopsies of solid mass lesions of the pancreas: A center's 10-year experience. Clin Imaging 39: 62-65, 2015

27. Yu YP, Jiang HT, Yao Z, Xia QR, Hong FM, Zeng H and Li S: Feasibility and safety of CT-guided percutaneous needle biopsy and subsequent iodine- 125 seed interstitial implantation for pancreatic cancer. Zhonghua Zhong Liu Za Zhi 35: 608-612, 2013 (In Chinese)

28. Karlson BM, Forsman CA, Wilander E, Skogseid B, Lindgren PG, Jacobson G and Rastad J: Efficiency of percutaneous core biopsy in pancreatic tumor diagnosis. Surgery 120: 75-79, 1996.

29. Dhall D, Mertens R, Bresee C, Parakh R, Wang HL, Li M, Dhall G, Colquhoun SD, Ines D, Chung F, et al: Ki-67 proliferative index predicts progression-free survival of patients with well-differentiated ileal neuroendocrine tumors. Hum Pathol 43 : 489-495, 2012

30. Couvelard A, Deschamps L, Ravaud P, Baron G, Sauvanet A, Hentic O, Colnot N, Paradis V, Belghiti J, Bedossa P, et al: Heterogeneity of tumor prognostic markers: A reproducibility study applied to liver metastases of pancreatic endocrine tumors. Mod Pathol 22: 273-281, 2009

31. Zen Y and Heaton N: Elevated Ki-67 labeling index in 'synchronous liver metastases' of well differentiated enteropancreatic neuroendocrine tumor. Pathol Int 63: 532-538, 2013.
32. Singh S, Hallet J, Rowsell C and Law CH: Variability of Ki67 labeling index in multiple neuroendocrine tumors specimens over the course of the disease. Eur J Surg Oncol 40: 1517-1522, 2014.

33. Grillo F, Albertelli M, Brisigotti MP, Borra T, Boschetti M, Fiocca R, Ferone D and Mastracci L: Grade increases in gastroEntero-pancreatic neuroendocrine tumor metastases compared to the primary tumor. Neuroendocrinology 103: 452-459, 2015.

34. Singh S, Dey C, Kennecke H, Kocha W, Maroun J, Metrakos P, Mukhtar T, Pasieka J, Rayson D, Rowsell C, et al: Consensus recommendations for the diagnosis and management of pancreatic neuroendocrine tumors: Guidelines from a Canadian National Expert group. Ann Surg Oncol 22: 2685-2699, 2015.

35. Falconi M, Bartsch DK, Eriksson B, Klöppel G, Lopes JM, O'Connor JM, Salazar R, Taal BG, Vullierme MP and O'Toole D; Barcelona Consensus Conference participants: ENETS Consensus Guidelines for the management of patients with digestive neuroendocrine neoplasms of the digestive system: Well-differentiated pancreatic non-functioning tumors. Neuroendocrinology 95: 120-134, 2012.

36. Kulke MH, Anthony LB, Bushnell DL, de Herder WW, Goldsmith SJ, Klimstra DS, Marx SJ, Pasieka JL, Pommier RF, Yao JC, et al; North American Neuroendocrine Tumor Society (NANETS): NANETS treatment guidelines: Well-differentiated neuroendocrine tumors of the stomach and pancreas. Pancreas 39: 735-752, 2010.

37. Öberg K, Knigge U, Kwekkeboom D and Perren A; ESMO Guidelines Working Group: Neuroendocrine gastro-enteropancreatic tumors: ESMO Clinical Practice Guidelines for diagnosis, treatment and follow-up. Ann Oncol 23 (Suppl 7): vii124-vii130, 2012.

38. Fischer L, Kleeff J, Esposito I, Hinz U, Zimmermann A, Friess H and Büchler MW: Clinical outcome and long-term survival in 118 consecutive patients with neuroendocrine tumours of the pancreas. Br J Surg 95: 627-635, 2008.

39. Pavel M, Baudin E, Couvelard A, Krenning E, Öberg K, Steinmüller T, Anlauf M, Wiedenmann B and Salazar R; Barcelona Consensus Conference participants: ENETS Consensus Guidelines for the management of patients with liver and other distant metastases from neuroendocrine neoplasms of foregut, midgut, hindgut, and unknown primary. Neuroendocrinology 95: 157-176, 2012.

40. Kunz PL, Reidy-Lagunes D, Anthony LB, Bertino EM, Brendtro K, Chan JA, Chen H, Jensen RT, Kim MK, Klimstra DS, et al; North American Neuroendocrine Tumor Society: Consensus guidelines for the management and treatment of neuroendocrine tumors. Pancreas 42: 557-577, 2013.

41. Edge SB, Byrd DR, Compton CC, Fritz AG, Greene FL and Trotti A: AJCC Cancer Staging Manual. Springer, New York, NY, 2010

42. Rindi G, Klöppel G, Alhman H, Caplin M, Couvelard A, de Herder WW, Erikssson B, Falchetti A, Falconi M, Komminoth P, et al; all other Frascati Consensus Conference participants; European Neuroendocrine Tumor Society (ENETS): TNM staging of foregut (neuro)endocrine tumors: A consensus proposal including a grading system. Virchows Arch 449: 395-401, 2006.

43. Norton JA, Warren RS, Kelly MG, Zuraek MB and Jensen RT: Aggressive surgery for metastatic liver neuroendocrine tumors. Surgery 134: 1057-1063, discussion 1063-1065, 2003.

44. Elias D, Lasser P, Ducreux M, Duvillard P, Ouellet JF, Dromain C, Schlumberger M, Pocard M, Boige V, Miquel C, et al: Liver resection (and associated extrahepatic resections) for metastatic well-differentiated endocrine tumors: A 15-year single center prospective study. Surgery 133: 375-382, 2003.

45. Watzka FM, Fottner C, Miederer M, Schad A, Weber MM, Otto G, Lang H and Musholt TJ: Surgical therapy of neuroendocrine neoplasm with hepatic metastasis: Patient selection and prognosis. Langenbecks Arch Surg 400: 349-358, 2015.

46. Mayo SC, de Jong MC, Pulitano C, Clary BM, Reddy SK, Gamblin TC, Celinksi SA, Kooby DA, Staley CA, Stokes JB, et al: Surgical management of hepatic neuroendocrine tumor metastasis: Results from an international multi-institutional analysis. Ann Surg Oncol 17: 3129-3136, 2010.

47. Steinmüller T, Kianmanesh R, Falconi M, Scarpa A, Taal B, Kwekkeboom DJ, Lopes JM, Perren A, Nikou G, Yao J, et al; Frascati Consensus Conference participants: Consensus guidelines for the management of patients with liver metastases from digestive (neuro)endocrine tumors: Foregut, midgut, hindgut, and unknown primary. Neuroendocrinology 87: 47-62, 2008. 
48. Sarmiento JM, Heywood G, Rubin J, Ilstrup DM, Nagorney DM and Que FG: Surgical treatment of neuroendocrine metastases to the liver: A plea for resection to increase survival. J Am Coll Surg 197: 29-37, 2003

49. Kandil E, Noureldine SI, Koffron A, Yao L, Saggi B and Buell JF: Outcomes of laparoscopic and open resection for neuroendocrine liver metastases. Surgery 152: 1225-1231, 2012.

50. Dousset B, Saint-Marc O, Pitre J, Soubrane O, Houssin D and Chapuis Y: Metastatic endocrine tumors: Medical treatment, surgical resection, or liver transplantation. World J Surg 20: 908-914, discussion 914-915, 1996

51. Kimura W, Tezuka K and Hirai I: Surgical management of pancreatic neuroendocrine tumors. Surg Today 41: 1332-1343, 2011.

52. Hanazaki K, Sakurai A, Munekage M, Ichikawa K, Namikawa T, Okabayashi T and Imamura M: Surgery for a gastroenteropancreatic neuroendocrine tumor (GEPNET) in multiple endocrine neoplasia type 1. Surg Today 43: 229-236, 2013.

53. Bloomston M, Muscarella P, Shah MH, Frankel WL, Al-Saif O, Martin EW and Ellison EC: Cytoreduction results in high perioperative mortality and decreased survival in patients undergoing pancreatectomy for neuroendocrine tumors of the pancreas. J Gastrointest Surg 10: 1361-1370, 2006.

54. Pavel M, O'Toole D, Costa F, Capdevila J, Gross D, Kianmanesh R, Krenning E, Knigge U, Salazar R, Pape UF, et al; Vienna Consensus Conference participants: ENETS consensus guidelines update for the management of distant metastatic disease of intestinal, pancreatic, bronchial neuroendocrine neoplasms (NEN) and NEN of unknown primary site. Neuroendocrinology 103: 172-185, 2016.

55. Maxwell JE, Sherman SK, O'Dorisio TM, Bellizzi AM and Howe JR: Liver-directed surgery of neuroendocrine metastases: What is the optimal strategy? Surgery 159: 320-333, 2016.

56. Gaujoux S, Gonen M, Tang L, Klimstra D, Brennan MF, D'Angelica M, Dematteo R, Allen PJ, Jarnagin W and Fong Y: Synchronous resection of primary and liver metastases for neuroendocrine tumors. Ann Surg Oncol 19: 4270-4277, 2012.

57. Zerbi A, Capitanio V, Boninsegna L, Delle Fave G, Pasquali C, Rindi G, Campana D and Falconi M; AISP-Network Study Group: Treatment of malignant pancreatic neuroendocrine neoplasms: Middle-term (2-year) outcomes of a prospective observational multicentre study. HPB Oxf 15: 935-943, 2013.

58. Cusati D, Zhang L, Harmsen WS, Hu A, Farnell MB, Nagorney DM, Donohue JH, Que FG, Reid-Lombardo KM and Kendrick ML: Metastatic nonfunctioning pancreatic neuroendocrine carcinoma to liver: Surgical treatment and outcomes. J Am Coll Surg 215: 117-124, discussion 124-125, 2012.

59. Mayo SC, de Jong MC, Bloomston M, Pulitano C, Clary BM, Reddy SK, Clark Gamblin T, Celinski SA, Kooby DA, Staley CA, et al: Surgery versus intra-arterial therapy for neuroendocrine liver metastasis: A multicenter international analysis. Ann Surg Oncol 18: 3657-3665, 2011

60. Bettini R, Mantovani W, Boninsegna L, Crippa S, Capelli P, Bassi C, Scarpa A, Pederzoli P and Falconi M: Primary tumour resection in metastatic nonfunctioning pancreatic endocrine carcinomas. Dig Liver Dis 41: 49-55, 2009.

61. Sarmiento JM and Que FG: Hepatic surgery for metastases from neuroendocrine tumors. Surg Oncol Clin N Am 12: 231-242, 2003.

62. Chambers AJ, Pasieka JL, Dixon E and Rorstad O: The palliative benefit of aggressive surgical intervention for both hepatic and mesenteric metastases from neuroendocrine tumors. Surgery 144: 645-651, discussion 651-653, 2008.

63. Hemming AW, Reed AI, Howard RJ, Fujita S, Hochwald SN, Caridi JG, Hawkins IF and Vauthey JN: Preoperative portal vein embolization for extended hepatectomy. Ann Surg 237: 686-691, discussion 691-693, 2003.

64. Yigitler C, Farges O, Kianmanesh R, Regimbeau JM, Abdalla EK and Belghiti J: The small remnant liver after major liver resection: How common and how relevant? Liver Transpl 9: S18-S25, 2003.

65. Goessmann H, Lang SA, Fichtner-Feigl S, Scherer MN, Schlitt HJ, Stroszczynski C, Schreyer AG and Schnitzbauer AA: Biliodigestive anastomosis: Indications, complications and interdisciplinary management. Chirurg 83: 1097-1108, 2012 (In German).

66. Kianmanesh R, Sauvanet A, Hentic O, Couvelard A, Lévy P, Vilgrain V, Ruszniewski $P$ and Belghiti J: Two-step surgery for synchronous bilobar liver metastases from digestive endocrine tumors: A safe approach for radical resection. Ann Surg 247: 659-665, 2008
67. Schnitzbauer AA, Lang SA, Goessmann H, Nadalin S, Baumgart J, Farkas SA, Fichtner-Feigl S, Lorf T, Goralcyk A, Hörbelt R, et al: Right portal vein ligation combined with in situ splitting induces rapid left lateral liver lobe hypertrophy enabling 2 -staged extended right hepatic resection in small-for-size settings. Ann Surg 255: 405-414, 2012.

68. Glazer ES, Tseng JF, Al-Refaie W, Solorzano CC, Liu P, Willborn KA, Abdalla EK, Vauthey JN and Curley SA: Long-term survival after surgical management of neuroendocrine hepatic metastases. HPB Oxf 12: 427-433, 2010.

69. Taner T, Atwell TD, Zhang L, Oberg TN, Harmsen WS, Slettedahl SW, Kendrick ML, Nagorney DM and Que FG: Adjunctive radiofrequency ablation of metastatic neuroendocrine cancer to the liver complements surgical resection. HPB Oxf 15: 190-195, 2013.

70. Frilling A and Clift AK: Therapeutic strategies for neuroendocrine liver metastases. Cancer 121: 1172-1186, 2015.

71. Frilling A, Sotiropoulos GC, Li J, Kornasiewicz O and Plöckinger U: Multimodal management of neuroendocrine liver metastases. HPB Oxf 12: 361-379, 2010.

72. Jagannath P, Chhabra D, Shrikhande S ans Shah R: Surgical treatment of liver metastases in neuroendocrine neoplasms. Int J Hepatol 2012: 782672, 2012 doi: 10.1155/2012/782672 .

73. Bertani E, Fazio N, Botteri E, Chiappa A, Falconi M, Grana C, Bodei L, Papis D, Spada F, Bazolli B, et al: Resection of the primary pancreatic neuroendocrine tumor in patients with unresectable liver metastases: Possible indications for a multimodal approach. Surgery 155: 607-614, 2014.

74. Nguyen SQ, Angel LP, Divino CM, Schluender S and Warner RR: Surgery in malignant pancreatic neuroendocrine tumors. J Surg Oncol 96: 397-403, 2007.

75. Basturk O, Yang Z, Tang LH, Hruban RH, Adsay V, McCall CM, Krasinskas AM, Jang KT, Frankel WL, Balci S, et al: The highgrade (WHO G3) pancreatic neuroendocrine tumor category is morphologically and biologically heterogenous and includes both well differentiated and poorly differentiated neoplasms. Am J Surg Pathol 39: 683-690, 2015.

76. Heetfeld M, Chougnet CN, Olsen IH, Rinke A, Borbath I, Crespo G, Barriuso J, Pavel M, O'Toole D and Walter T; other Knowledge Network members: Characteristics and treatment of patients with G3 gastroenteropancreatic neuroendocrine neoplasms. Endocr Relat Cancer 22: 657-664, 2015.

77. Ilett EE, Langer SW, Olsen IH, Federspiel B, Kjær A and Knigge U: Neuroendocrine carcinomas of the gastroenteropancreatic system: A comprehensive review. Diagnostics Basel 5: 119-176, 2015.

78. Panzuto F, Boninsegna L, Fazio N, Campana D, Pia Brizzi M, Capurso G, Scarpa A, De Braud F, Dogliotti L, Tomassetti P, et al: Metastatic and locally advanced pancreatic endocrine carcinomas: Analysis of factors associated with disease progression. J Clin Oncol 29: 2372-2377, 2011.

79. Cho MY, Kim JM, Sohn JH, Kim MJ, Kim KM, Kim WH, Kim H, Kook MC, Park DY, Lee JH, et al; Gastrointestinal Pathology Study Group of Korean Society of Pathologists: Current Trends of the Incidence and Pathological Diagnosis of Gastroenteropancreatic Neuroendocrine Tumors (GEP-NETs) in Korea 2000-2009: Multicenter Study. Cancer Res Treat 44: 157-165, 2012.

80. Strosberg JR, Coppola D, Klimstra DS, Phan AT, Kulke MH, Wiseman GA and Kvols LK; North American Neuroendocrine Tumor Society (NANETS): The NANETS consensus guidelines for the diagnosis and management of poorly differentiated (highgrade) extrapulmonary neuroendocrine carcinomas. Pancreas 39: 799-800, 2010

81. Nilsson O, Van Cutsem E, Delle Fave G, Yao JC, Pavel ME, McNicol AM, Sevilla Garcia MI, Knapp WH, Keleştimur F, Sauvanet A, et al; Frascati Consensus Conference; European Neuroendocrine Tumor Society: Poorly differentiated carcinomas of the foregut (gastric, duodenal and pancreatic). Neuroendocrinology 84: 212-215, 2006.

82. Akerström G: Management of carcinoid tumors of the stomach, duodenum, and pancreas. World J Surg 20: 173-182, 1996.

83. Kölby L, Nilsson O and Ahlman H: Gastroduodenal endocrine tumours. Scand J Surg 93: 317-323, 2004.

84. Du S, Ni J, Weng L, Ma F, Li S, Wang W, Sang X, Lu X, Zhong S and Mao Y: Aggressive locoregional treatment improves the outcome of liver metastases from grade 3 gastroenteropancreatic neuroendocrine tumors. Medicine (Baltimore) 94: e1429, 2015. 
85. Haugvik SP, Janson ET, Österlund P, Langer SW, Falk RS, Labori KJ, Vestermark LW, Grønbæk H, Gladhaug IP and Sorbye H: Surgical treatment as a principle for patients with high-grade pancreatic neuroendocrine carcinoma: A Nordic multicenter comparative study. Ann Surg Oncol 23: 1721-1728, 2016.

86. Schweizer RT, Alsina AE, Rosson R and Bartus SA: Liver transplantation for metastatic neuroendocrine tumors. Transplant Proc 25: 1973, 1993

87. Lehnert T: Liver transplantation for metastatic neuroendocrine carcinoma: An analysis of 103 patients. Transplantation 66: $1307-1312,1998$.

88. Olausson M, Friman S, Herlenius G, Cahlin C, Nilsson O, Jansson S, Wängberg B and Ahlman H: Orthotopic liver or multivisceral transplantation as treatment of metastatic neuroendocrine tumors. Liver Transpl 13: 327-333, 2007.

89. Frilling A, Malago M, Weber F, Paul A, Nadalin S, Sotiropoulos GC, Cicinnati V, Beckebaum S, Bockisch A, Mueller-Brand J, et al: Liver transplantation for patients with metastatic endocrine tumors: Single-center experience with 15 patients. Liver Transpl 12: 1089-1096, 2006.
90. van Vilsteren FG, Baskin-Bey ES, Nagorney DM, Sanderson SO, Kremers WK, Rosen CB, Gores GJ and Hobday TJ: Liver transplantation for gastroenteropancreatic neuroendocrine cancers: Defining selection criteria to improve survival. Liver Transpl 12: 448-456, 2006.

91. Rosenau J, Bahr MJ, von Wasielewski R, Mengel M, Schmidt HH, Nashan B, Lang H, Klempnauer J, Manns MP and Boeker KH: Ki67, E-cadherin, and p53 as prognostic indicators of long-term outcome after liver transplantation for metastatic neuroendocrine tumors. Transplantation 73: 386-394, 2002.

92. Le Treut YP, Grégoire E, Klempnauer J, Belghiti J, Jouve E, Lerut J, Castaing D, Soubrane O, Boillot O, Mantion G, et al; For ELITA: Liver transplantation for neuroendocrine tumors in Europe-results and trends in patient selection: A 213-case European liver transplant registry study. Ann Surg 257: 807-815, 2013.

93. Mazzaferro V, Pulvirenti A and Coppa J: Neuroendocrine tumors metastatic to the liver: How to select patients for liver transplantation? J Hepatol 47: 460-466, 2007. 